\title{
PENGENDALIAN KUALITAS PRODUK MEBEL DENGAN PENDEKATAN METODE NEW SEVEN TOOLS
}

\author{
Nurul Aziza ${ }^{1}$, Fajar Bayu Setiaji² \\ Teknik Industri, Fakultas Teknik \\ Universitas Maarif Hasyim Latif, Sidoarjo, Indonesia \\ e-mail : ${ }^{1}$ nurul_aziza@dosen.umaha.ac.id, ${ }^{2}$ kiplibayu19@gmail.com \\ Diterima: 24 April 2020. Disetujui : 20 Juni 2020. Dipublikasikan : 30 Juni 2020 \\ (C)2020 -TESJ Fakultas Teknik Universitas Maarif Hasyim Latif. Ini adalah artikel dengan \\ akses terbuka di bawah lisensi CC BY 4.0 (https://creativecommons.org/licenses/by/4.0/)
}

\begin{abstract}
ABSTRAK
Perusahaan memproduksi mebel berorientasi ekspor ke Amerika bersifat job order. Pemesanan skala ekspor ke luar negeri menuntut kualitas tinggi dengan bahan baku yang baik. Bahan baku utama produk mebel antara lain kayu meranti putih, meranti merah, dan mahoni yang berasal dari Kalimantan, dan rotan sebagai bahan penunjang. Pada saat proses produksi masih ditemukan defect yang berupa baret, skrup muncul, rompak kayu, bluestain (serat kayu tidak standar) dan mata kayu. Untuk menjamin kualitas dan meminimasi jumlah defect, maka perlu dilakukan penelitian untuk mengetahui faktor-faktor apa saja yang menyebabkan kecacatan produk agar dapat dilakukan perbaikan secara kualitatif dengan metode new seven tools yaitu affinity diagram, interrelationship diagram, tree diagram, matrix diagram, activity network diagram, pdpc (process decision program chart), matrix data analysis. Berdasarkan hasil pengolahan dan analisis didapatkan bahwa faktor-faktor penyebab kecacatan produk pada mebel adalah kurangnya kemampuan dan ketelitian operator menguasai mesin. Faktor mesin juga menjadi penyebab cacat. Sehingga evaluasi perbaikan yang dapat dilakukan adalah melakukan pelatihan dan sosialiasasi SOP pengoperasian mesin dan melakukan maintenance secara berkala.
\end{abstract}

Kata kunci: defect, new seven tools, pengendalian kualitas

\section{PENDAHULUAN}

PT. MMI adalah suatu perusahaan yang memproduksi kayu menjadi barang jadi (furniture), seperti tempat tidur, meja, kursi, dan lemari. Produk perusahaan ini telah diekspor ke Amerika bersifat "job order" yang berarti besarnya produksi yang tergantung pada permintaan atau pesanan dari konsumen. Bahan baku utama untuk pembuatan produk mebel yaitu kayu meranti putih, meranti merah, dan mahoni yang berasal dari Kalimantan serta rotan sebagai bahan baku penunjang.

Proses pembuatan produk masih ditemukan produk cacat berupa baret, skrup muncul, rompak kayu, bluestain (serat kayu tidak standar) dan mata kayu. Oleh karena itu perlu diketahui faktor-faktor apa saja yang menyebabkan defect produk agar dapat dilakukan perbaikan untuk mengurangi produk cacat. Tujuan dari penelitian ini ialah untuk mengidentifikasi faktor-faktor penyebab kecacatan yang terjadi pada produk dan memberikan usulan solusi untuk mengurangi persentase kecacatan dalam produk Metode new seven tools juga digunakan pada penelitian kualitatif (Chandradevi \& Puspitasari, 2016). Teknik pengendalian kualitas ini sebagai tujuh alat bantu pengendalian kualitas dengan hasil terjamin dan sukses untuk perusahaan sebagai kontrol kualitas (Mizuno, 2020). New seven tools of quality adalah tujuh alat bantu yang mampu mengeksplorasi data secara kualitatif (Hui et al., 2013). Penelitian (Rahayuningtyas \& Sriyanto, 2018) juga menjadi dasar penelitian ini untuk mengurangi cacat pada produk tahu bakso. Pengendalian kualitas bisa dilakukan dengan menggabungkan new seven tools dengan six sigma dan kaizen (Wisnubroto \& Rukmana, 2015). Pengendalian kualitas untuk mengurangi defect di PT. Dirgantara juga dilakukan dengan menggunakan metode new seven tools (Ginting \& Fattah, 2020). Namun penerapan total manajemen kualitas dapat berhasil dengan memanfaatkan alat dan teknik manajemen mutu yang sesuai (Pramono et al., 2018). Peningkatan kualitas juga bisa menggunakan implementasi teknik data mining agar masalah kualitas dapat terselesaikan (Tsironis, 2018).

\section{METODE PENELITIAN}

Urutan metodologi penelitian ini dapat dilihat pada Gambar 1. 


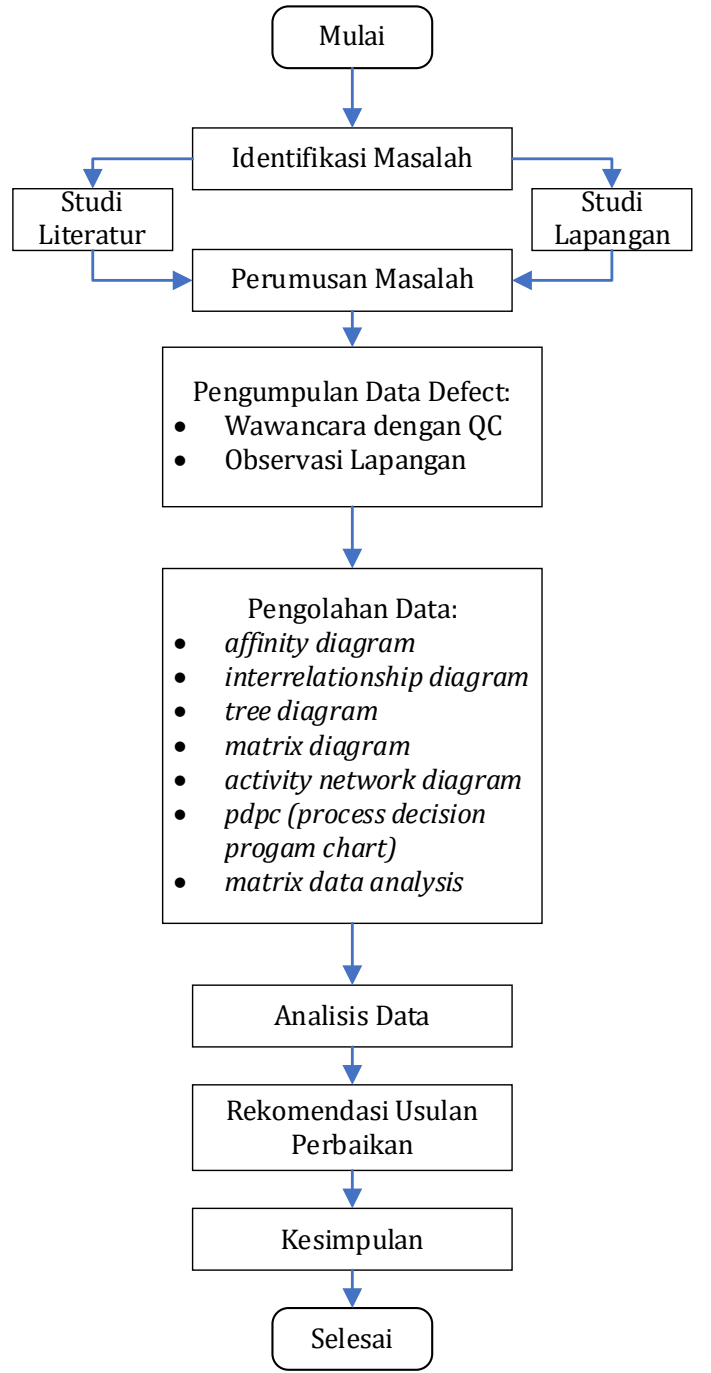

Gambar 1. Diagram alur penelitian

\section{Affinity diagram}

Affinity diagram digunakan untuk mengumpulkan dan mengorganisir sejumlah fakta, opini, dan ide. Selain itu juga memacu kreativitas yang mendorong pengungkapan batas fakta dan opini serta kondisi yang ada melalui pengelompokkan elemen-elemen informasi tersebut sesuai dengan kesamaan dan pertaliannya (Pramono et al., 2018).

\section{Interrelationship Diagram}

Diagram hubungan merupakan alat untuk menemukan pemecahan masalah yang memiliki hubungan kausal yang kompleks. Hal ini membantu untuk menguraikan dan menemukan hubungan logis yang saling terkait antara sebab dan akibat (Kusnadi, 2014).

\section{Diagram Pohon}

Diagram pohon adalah teknik untuk memetakan lengkap jalur dan tugas-tugas yang perlu dilakukan dalam rangka untuk mencapai tujuan utama dan tujuan sub terkait. Diagram ini mengungkapkan secara sederhana besarnya masalah dan membantu untuk sampai pada metode-metode yang harus dikejar untuk mencapai hasil (Dianmardi, 2011).

\section{Matrix Diagram}

Diagram Matriks menunjukkan hubungan antara dua, tiga, atau empat kelompok informasi. Terdiri dari sejumlah kolom dan baris untuk mengetahui sifat dan kekuatan dari masalah. Ini akan membantu kita untuk sampai pada ide utama dan menganalisis hubungan atau tidak adanya di persimpangan dan menemukan cara yang efektif untuk mengejar metode pemecahan masalah (Dianmardi, 2011).

\section{Activity Network Diagram}

Diagram ini digunakan untuk merencanakan atau menjadwalkan proyek. Dengan activity network diagram dapat dilakukan analisis terhadap jadwal waktu penyelesaian proyek, masalah yang timbul jika terjadi keterlambatan, probability penyelesaian proyek, dan biaya yang diperlukan untuk mempercepat penyelesaian proyek.

\section{Process Decision Program Chart (PDPC)}

Process Decision Program Chart Method merupakan metode yang digunakan untuk mengidentifikasi masalah-masalah yang berpotensi muncul dan mengidentifikasi tindakan pencegahan dalam suatu rencana (Sepsarianto, 2013).

\section{Analisis Diagram Matriks}

Analisis diagram matriks adalah diagram analisis data numerik berbentuk matriks yang menghasilkan komponen utama pengganti variabel yang berpengaruh pada suatu masalah. Analisis data matriks juga dapat mengatasi kesulitan atau kelemahan regresi multi variabel melalui penggunaan komputer (Michalski \& Mosig, 1997).

\section{HASIL DAN PEMBAHASAN}

Berdasarkan pengumpulan dan pengolahan data didapatkan defect produk seperti digambarkan pada Gambar 2.

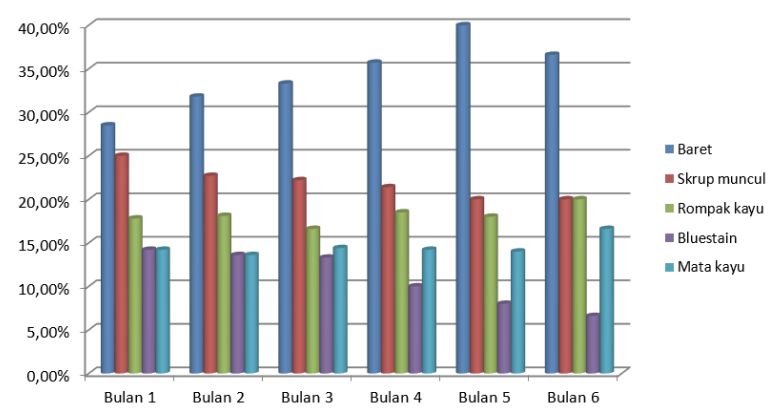

Gambar 2. Grafik jumlah persentase jenis defect tiap bulan 
Sedangkan berikut hasil metode new seven tools yang digunakan:

\section{Affinity diagram}

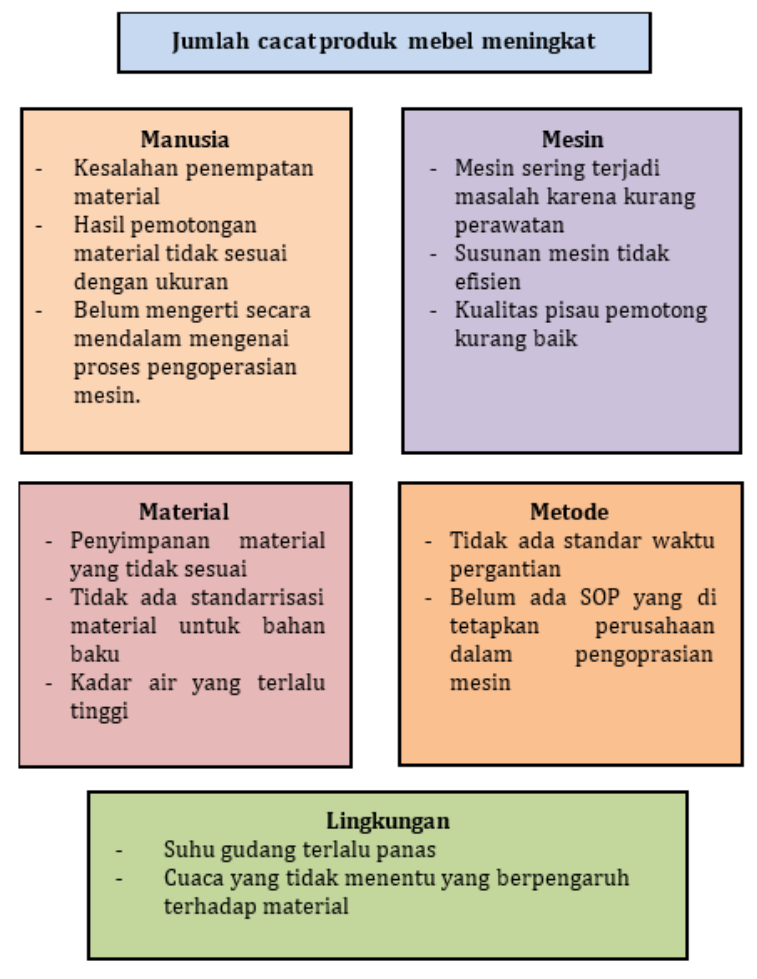

Gambar 3. Affinity diagram

Berdasarkan analisis affinity diagram seperti pada Gambar 3, faktor penyebab defect disebabkan oleh manusia, mesin, material, metode dan lingkungan. Dan di setiap faktor memiliki permasalahan yang dapat menimbulkan defect. Terjadinya defect yang disebabkan oleh faktor manusia yaitu kesalahan dalam penempatan material, belum mengerti secara mendalam mengenai proses pengoprasian mesin. Faktor mesin terjadi karena mesin terjadi masalah karena kurangnya perawatan, kualitas pisau pemotong kurang baik. Faktor material dikarenakan penyimpanan material yang tidak sesuai, tidak ada standarrisasi material untuk dijadikan bahan baku. Penyimpanan material di ruang terbuka sehingga kadar air bahan baku tinggi karena terkena air hujan. Faktor metode tidak ada standar waktu pergantian operator. Faktor lingkungan cuaca yang tidak menentu yang berpengaruh terhadap material.

\section{Interrelationship Diagram}

Interrelationship diagram ini membantu untuk menguraikan dan menemukan hubungan logis yang saling terkait antara sebab dan akibat permasalahan jumlah cacat produk mebel di PT MMI.

Berdasarkan interrelationship diagram di Gambar 4 menunjukkan anak panah yang bertumpu pada mesin yang sering terjadi masalah dikarenakan kualitas pisau kurang baik, mesin jarang dilakukan maintenance, tidak ada standar waktu pergantian operator, dan tidak ada SOP pengoperasian mesin. Kemudian kesalahan operator saat mengoperasikan mesin disebabkan oleh operator belum menguasai pengoprasian mesin dan tidak ada SOP pengoperasian mesin. Penyimpanan material yang kurang baik bisa menyebabkan kadar air pada material terlalu tinggi.

\section{Tree Diagram}

Dengan metode tree diagram dapat mengurangi jumlah cacat produk mebel di PT MMI dengan cara:

1. Meningkatkan kinerja operator dengan mengkaji ulang pengoperasian mesin melalui diskusi

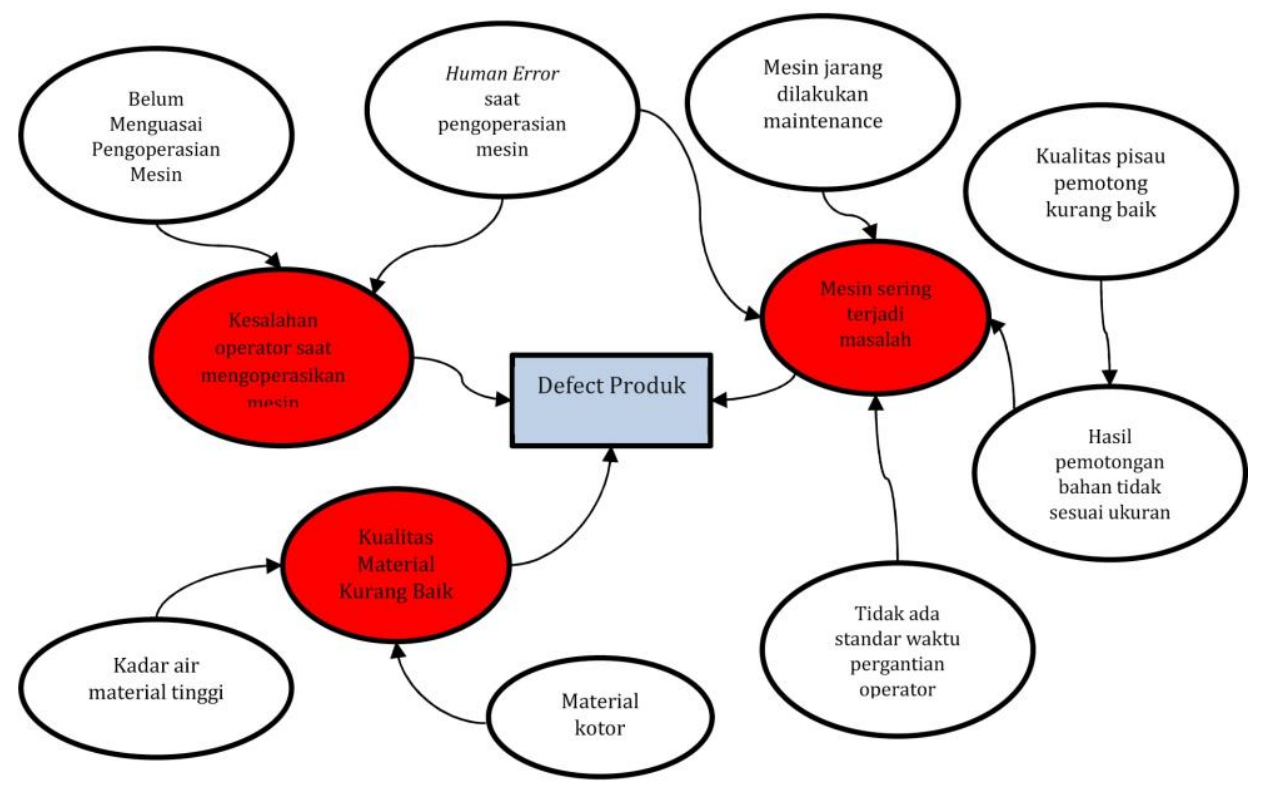

Gambar 4. Interrelationship diagram 


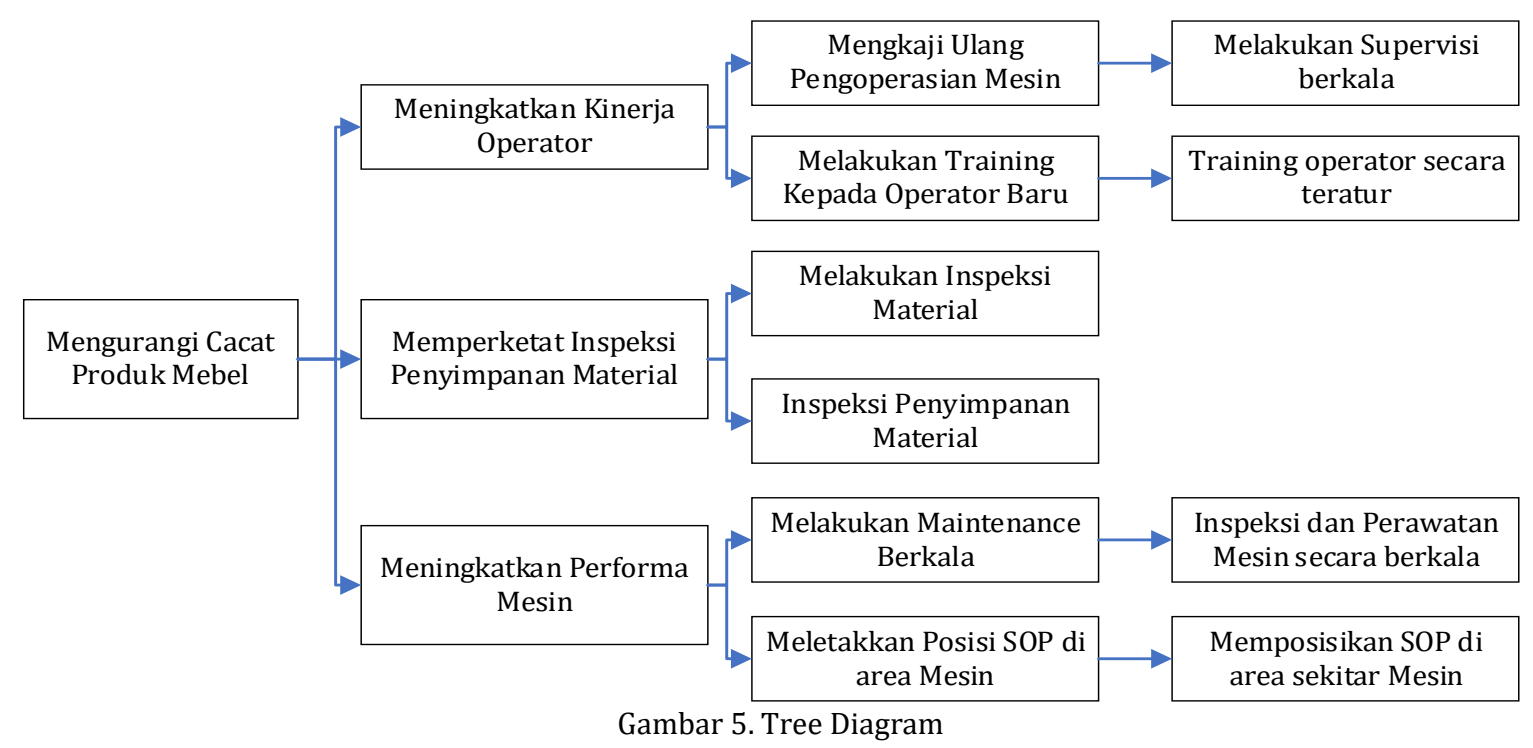

dengan supervisor dan operator sebelum memulai pekerjaan, melakukan training pada operator baru selama satu tahun penuh.

2. Memperketat inspeksi penyimpanan material yang meliputi melakukan pengecekan material dan pengecekan tempat penyimpanan material.

3. Meningkatkan performa kinerja mesin dengan melakukan maintenance secara teratur selama dua bulan sekali dan meletakkan SOP di area mesin.

\section{Matrix diagram}

\begin{tabular}{|c|c|c|c|}
\hline $\begin{array}{l}\text { Kesalahan operator } \\
\text { menggunakan mesin }\end{array}$ & & & \\
\hline $\begin{array}{l}\text { Mesin yang sering terjadi } \\
\text { masalah }\end{array}$ & & & \\
\hline $\begin{array}{l}\text { kualitas material yang } \\
\text { kurang baik }\end{array}$ & & & \\
\hline Faktor - faktor & \multirow[b]{2}{*}{$\begin{array}{c}\text { Meningkatkan } \\
\text { kinerja operator }\end{array}$} & \multirow{2}{*}{$\begin{array}{c}\text { Memperketat } \\
\text { proses } \\
\text { penyimpanan } \\
\text { material }\end{array}$} & \multirow[b]{2}{*}{$\begin{array}{l}\text { Meningkatkan } \\
\text { performa mesin }\end{array}$} \\
\hline \begin{tabular}{|l}
\multicolumn{2}{c}{ Aktivitas perbaikan } \\
Aktivitas spesifik \\
\end{tabular} & & & \\
\hline \multicolumn{4}{|l|}{$\begin{array}{l}\text { Melakukan pengecekan dan } \\
\text { perawatan mesin }\end{array}$} \\
\hline \multicolumn{4}{|l|}{$\begin{array}{l}\text { Mengkaji ulang proses } \\
\text { pengoprasian mesin }\end{array}$} \\
\hline \multicolumn{4}{|l|}{$\begin{array}{l}\text { Melakukan pengecekan } \\
\text { material yang akan di pakai }\end{array}$} \\
\hline \multicolumn{4}{|l|}{\begin{tabular}{|l|} 
Melakukan pengecekan \\
penyimpanan material
\end{tabular}} \\
\hline \multicolumn{4}{|l|}{$\begin{array}{l}\text { Menggunakan checksheet } \\
\text { agar jenis cacat dapat } \\
\text { direkap }\end{array}$} \\
\hline \multicolumn{4}{|l|}{$\begin{array}{l}\text { Melakukan training kepada } \\
\text { operator baru dalam } \\
\text { penggunaan mesin } \\
\end{array}$} \\
\hline \multicolumn{4}{|l|}{$\begin{array}{l}\text { Meletakkan SOP disekitar } \\
\text { penggunaan mesin yang } \\
\text { digunakan }\end{array}$} \\
\hline \multicolumn{4}{|l|}{ Keterangan: } \\
\hline \multicolumn{4}{|c|}{ sangat berkaitan } \\
\hline \multicolumn{4}{|l|}{ berkaitan } \\
\hline tidak berkai & & & \\
\hline
\end{tabular}

Matrix diagram adalah alat yang sering digunakan untuk menggambarkan tindakan yang diperlukan untuk suatu perbaikan proses atau produk. Tingginya jumlah produk cacat mebel yang tidak terkendali ini menggunakan matriks bentuk T dengan mengidentifikasi hubungan antar aktivitas perbaikan dengan aktivitas spesifik dan faktorfaktor berpengaruh pada variansi produk cacat produk. Diagram matriks T dapat dilihat pada Tabel 1.

Untuk mengetahui departemen apa saja yang bertanggung jawab terkait dengan terjadinya kecacatan produk, yang meliputi perbaikan defect yang digambarkan dalam matrix diagram. Untuk penjelasan simbol persegi, segitiga dan lingkaran yaitu untuk simbol persegi melambangkan bahwa sangat berkaitan, simbol segitiga melambangkan bahwa berkaitan, dan lingkaran melambangkan tidak ada keterkaitan. berdasarkan matrix diagram Tabel 1, maka bisa dilakukan analisis yaitu:

1. Faktor-faktor, aktivitas perbaikan, dan aktivitas spesifik yang sangat berkaitan adalah kesalahan operator dalam mengoperasikan mesin dengan mengkaji ulang proses pengoperasian mesin sehingga mampu meningkatkan kinerja operator. Performa mesin yang kurang optimal dengan melakukan pengecekan dan perawatan mesin dapat meningkatkan kinerja operator. sehingga memiliki simbol persegi

2. Faktor-faktor, aktivitas perbaikan, dan aktivitas spesifik yang berkaitan adalah penyimpanan material yang kurang baik dengan pengecekan material yang akan di pakai dapat memperketat dalam proses penyimpanan material. sehingga memiliki simbol segitiga

3. Faktor-faktor, aktivitas perbaikan, dan aktivitas spesifik yang tidak berkaitan yaitu performa mesin yang kurang optimal dengan melakukan pengecekan penyimpanan material tidak ada kaitannya dengan meingkatkan performa mesin. sehingga memiliki simbol lingkaran.

\section{Activity network diagram}

Diagram ini digunakan untuk merencanakan atau menjadwalkan proyek. Dengan activity network diagram dapat dilakukan analisis terhadap 
jadwal waktu penyelesaian proyek, masalah yang timbul jika terjadi keterlambatan, probability penyelesaian proyek, dan biaya yang diperlukan untuk mempercepat penyelesaian proyek. Tabel 2 . menunjukkan jenis kegiatan dan waktu.

Tabel 2. Jenis Kegiatan dan Waktu

\begin{tabular}{lccc}
\hline \multicolumn{1}{c}{ Jenis Kegiatan } & $\begin{array}{c}\text { Kode } \\
\text { Kegiatan }\end{array}$ & $\begin{array}{c}\text { Kegiatan } \\
\text { sebelumnya }\end{array}$ & Durasi \\
\hline Membuat desain & A & - & 10 hari \\
$\begin{array}{l}\text { Proses pemotongan } \\
\text { material }\end{array}$ & B & A & 7 hari \\
Bagian R\&D & C & A & 4 hari \\
Proses bor & D & B,C & 2 hari \\
Perakitan di bagian & E & D & 4 hari \\
assembling & F & E & 3 hari \\
Proses amplas & G & F & 4 hari \\
Proses cat & H & G & 3 hari \\
Bagian finishing & I & H & 2 hari \\
Packing & & &
\end{tabular}

Berdasarkan Tabel 2 maka activity network diagram dapat dilihat pada Gambar 6. Berdasarkan activity network diagram pada Gambar 6 maka proses pembuatan meja dan kursi memerlukan waktu 31 hari. Dan memiliki lintasan yang kritis yaitu A-B-D-F-G-H-I, maka kegiatan A dalam pembuatan desain harus sesuai dengan durasi yang sudah dijadwalkan yaitu selama 10 hari. Apabila terjadi keterlambatan dalam proses tersebut maka dapat terjadi keterlambatan dalam proses berikutnya dan membutuhkan waktu yang lebih banyak lagi.

\section{Process Decision Program Chart (PDPC)}

Diagram ini digunakan untuk memetakan kegiatan situasi yang mungkin terjadi sehingga PDPC dibuat untuk tujuan pemecahan akhir dari suatu masalah. Diagram ini dapat membantu dalam menentukan proses yang akan digunakan untuk mendapatkan hasil yang diinginkan dengan mengevaluasi kemajuan dari peristiwa dan hasil yang memungkinkan.

Berdasarkan Gambar 7 PDPC menunjukkan bahwa jumlah cacat mebel dapat terkendali apabila

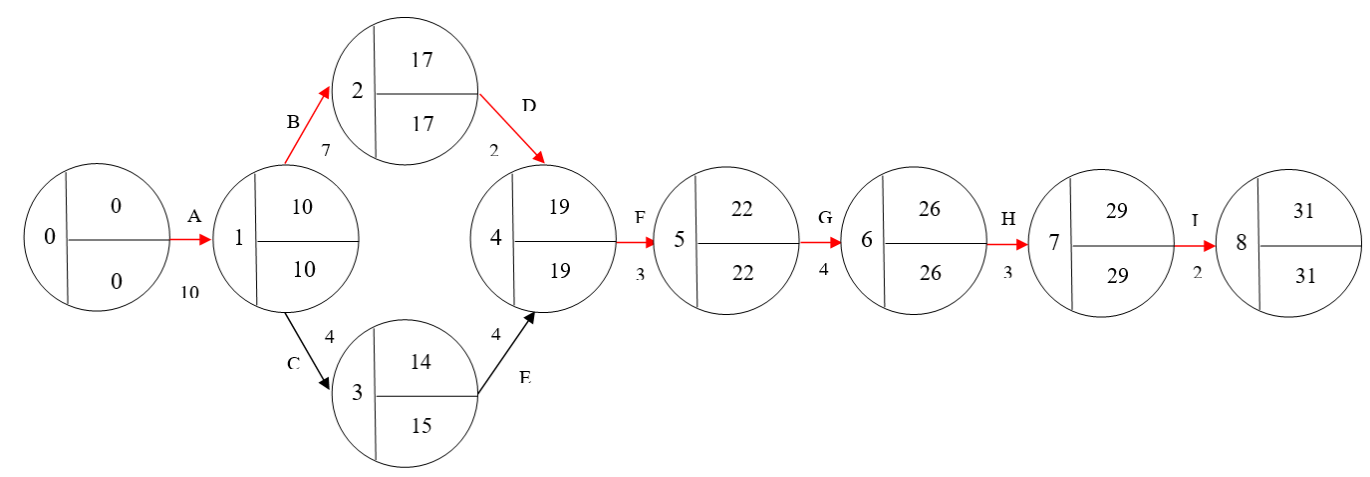

Gambar 6. Activity network diagram

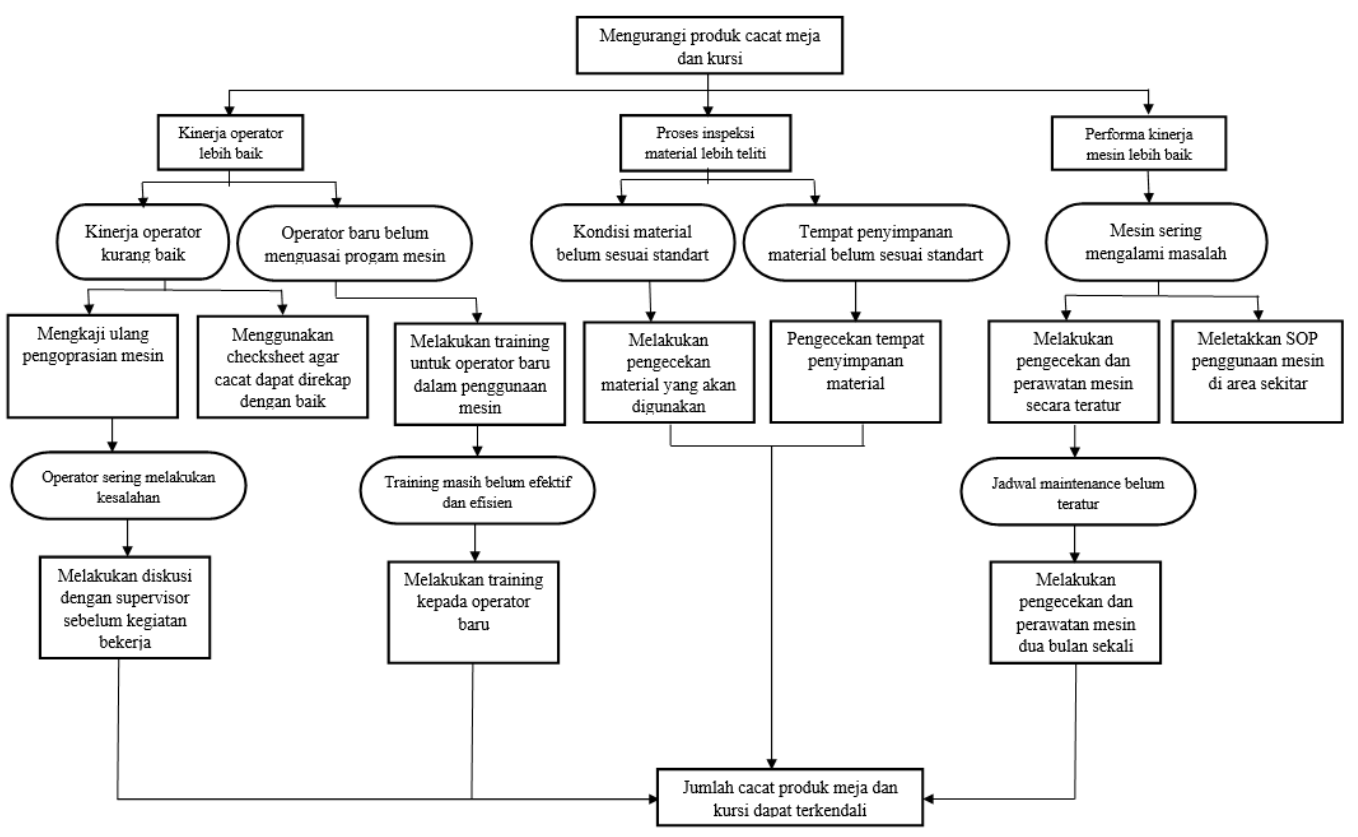

Gambar 7. Process Decision Program Chart 
masalah-masalah potensial ini tidak terjadi yang disebabkan oleh operator sering melakukan kesalahan, operator belum menguasai program mesin, tempat penyimpanan material belum sesuai standart dan mesin sering terjadi masalah. Maka upaya penanggulangan yang memungkinkan adalah dengan melakukan diskusi dengan supervisor sebelum kegiatan bekerja, melakukan training kepada operator baru, dan melakukan pengecekan dan perawatan mesin secara berkala.

\section{Matrix Data Analysis}

Adalah alat (tools) yang digunakan untuk mengambil data yang ditampilkan dalam matrix diagram sehingga dapat lebih mudah diperlihatkan dan menunjukkan kekuatan hubungan antar variabel. Pengisian tabel tersebut dilakukan bersama dengan koordinator pengawas yang ada di PT. MMI dan dapat dilihat pada Tabel 3. Dalam diagram matrix data anlysis ini di PT. MMI meningkatkan kinerja operator dengan mengkaji ulang proses pengoperasian mesin ini melalui training kepada operator baru di perusahaan agar memahami pengoperasian mesin. Sedangkan untuk memperketat penyimpanan material di perusahaan, maka dilakukan pengecekan terlebih dahulu untuk material yang akan digunakan. Untuk meningkatkan performa mesin di PT. MMI melakukan maintenance mesin secara berkala.

\begin{tabular}{|c|c|c|c|}
\hline Primary & Secondary & importance & PT. MMI \\
\hline \multirow[t]{2}{*}{$\begin{array}{l}\text { Meningkatkan } \\
\text { kinerja } \\
\text { operator }\end{array}$} & $\begin{array}{l}\text { Mengkaji ulang } \\
\text { proses } \\
\text { pengoperasian } \\
\text { mesin }\end{array}$ & 2 & 3 \\
\hline & $\begin{array}{l}\text { Melakukan } \\
\text { training kepada } \\
\text { operator baru }\end{array}$ & 3 & 3 \\
\hline \multirow[t]{2}{*}{$\begin{array}{l}\text { Memperketat } \\
\text { penyimpanan } \\
\text { material }\end{array}$} & $\begin{array}{l}\text { Melakukan } \\
\text { pengecekan } \\
\text { material yang akan } \\
\text { digunakan }\end{array}$ & 2 & 3 \\
\hline & $\begin{array}{l}\text { Melakukan } \\
\text { pengecekan } \\
\text { penyimpanan } \\
\text { material }\end{array}$ & 2 & 2 \\
\hline \multirow[t]{2}{*}{$\begin{array}{l}\text { Meningkatkan } \\
\text { performa } \\
\text { mesin }\end{array}$} & $\begin{array}{l}\text { Melakukan } \\
\text { pengecekan dan } \\
\text { perawatan mesin } \\
\text { secara berkala }\end{array}$ & 2 & 2 \\
\hline & $\begin{array}{l}\text { Meletakkan SOP } \\
\text { penggunaan mesin }\end{array}$ & 3 & 2 \\
\hline \multicolumn{4}{|c|}{$\begin{array}{l}\text { Keterangan: } \\
1: \text { belum dilakukan } \\
2: \text { dilakukan } \\
3: \text { sering dilakukan }\end{array}$} \\
\hline
\end{tabular}

\section{PENUTUP}

Berdasarkan hasil penelitian di atas dapat disimpulkan faktor-faktor penyebab kecacatan produk mebel PT Multi Manao Indonesia adalah operator belum menguasai pengoperasian mesin, kurang teliti pengoperasian mesin dan kurangnya pengawasan terhadap operator. Mesin sering terjadi masalah karena kurangnya pengecekan dan perawatan mesin tidak secara teratur. Cacat material dikarenakan tidak ada SOP dan tempat penyimpanan material yang kurang baik.

Maka evaluasi perbaikan yang dapat dilakukan adalah mengkaji ulang prosedur pengoperasian mesin dengan melakukan training kepada operator selama satu tahun penuh, melakukan maintenance mesin secara berkala dan penyiapan ruangan penyimpanan bahan baku.

\section{DAFTAR PUSTAKA}

Chandradevi, A., \& Puspitasari, N. B. (2016). Analisa Pengendalian Kualitas Produksi Botol X 500 Ml Pada PT. Berlina, Tbk Dengan Menggunakan Metode New Seven Tools. Industrial Engineering Online Journal, 5(4).

Ginting, R., \& Fattah, M. G. (2020). Production quality control with new seven tools for defect minimization on PT. Dirgantara Indonesia. In IOP Conference Series: Earth and Environmental Science (Vol. 452, p. 12082). IOP Publishing.

Hui, Z., Ming, S., Cheng, L., Hong-Fang, C., Yue-Kun, H., Yong-Jie, S., ... Shuai, Y. (2013). A GEANT4 simulation study of BESIII endcap TOF upgrade. Chinese Physics C, 37(9), 96002.

Kusnadi, M. A. (2014). Hubungan Antara Beban Kerja dan Self-Efficacy dengan Stres Kerja pada Dosen Universitas X. CALYPTRA, 3(1), $1-15$.

Michalski, K. A., \& Mosig, J. R. (1997). Multilayered media Green's functions in integral equation formulations. IEEE Transactions on Antennas and Propagation, 45(3), 508-519.

Mizuno, S. (2020). Management for quality improvement: the 7 new QC tools. CRC Press.

Pramono, S. N. W., Ulkhaq, M. M., Rachmadina, D. P., Trianto, R., Rachmadani, A. P., Wijayanti, W. R., \& Dewi, W. R. (2018). The Use of Quality Management Techniques: The Application of the New Seven Tools. International Journal of Applied Science and Engineering, 15(2), 105112.

Rahayuningtyas, W., \& Sriyanto, S. (2018). ANALISIS PENGENDALIAN KUALITAS PADA PRODUK TAHU BAXO IBU PUDJI MENGGUNAKAN METODE NEW SEVEN TOOLS (Studi Kasus pada CV. Pudji Lestari Sentosa). Industrial Engineering Online Journal, 6(4).

Sepsarianto, R. (2013). Analisis Masalah 7 Tools. URL: Http://Www. Scribd. Com/Doc/189322119/Analisis-Masalah-7Tools (13 Agustus 2013). 
Tsironis, L. K. (2018). Quality improvement calls data mining: the case of the seven new quality tools. Benchmarking: An International Journal.

Wisnubroto, P., \& Rukmana, A. (2015). Pengendalian kualitas produk dengan pendekatan six sigma dan analisis kaizen serta new seven tools sebagai usaha pengurangan kecacatan produk. Jurnal Teknologi, 8(1), 65-74. 
N Aziza, dkk / Teknika : Engineering and Sains Journal, Vol. 4, No.1, Juni 2020, 27-34

halaman ini sengaja dikosongkan 